\title{
A simple technique for ureteral orifice dilatation in rigid ureterorenoscopy for distal ureteral stones
}

\section{Cevahir Özer, MD}

Nobel Surgical Medical Center, Division of Urology, Adana, Turkey

Cite as: Can Urol Assoc J 2011;5(6):E119-E120; D01:10.5489/Cuaj.11004

W e describe a simple technique for ureteral orifice dilatation before rigid ureterorenoscopy for distal ureteral stones.

\section{Introduction}

Advances in technology have led to the development of smaller caliber ureteroscopes. ${ }^{1}$ Currently, small size rigid ureteroscopes are passed atraumatically into the ureter without prior dilation. However, this is not always possible, and in some cases ureteral dilation is required. Here is a simple technique, which does not require special device, for ureteral orifice dilatation before ureterorenoscopy for distal ureteral stones.

\section{Technique}

After failing to place a ureter catheter and guidewire because of distal ureteral stone that caused obstruction, I tried to enter the ureter by ureteroscope without dilatation. After failing with this, I passed forceps through the working channel of the ureteroscope and entered the ureter. The intramural segment of the ureter was partially opened when the position of the jaws was vertical; the forceps were then gently withdrawn (Fig. 1). After this process was repetated several times, the ureteroscope easily passed by itself, and the stone was fragmentated with pneumatic lithotriptor. Perforation, avulsion or false passage of the ureter did not occur. The postoperative period was uneventful and the follow-up intravenous urogram was normal.

\section{Discussion}

Dilation should be simple, efficient, fast and cause minimal or no iatrogenic trauma. ${ }^{2}$ Several different techniques have been described for the ureteral dilatation before ureterorenoscopy. All of these techniques require a spesific device (balloon dilators, mechanical dilating devices such as teflon or polyethylene dilators, telescoping metal ureteral dilators, metal bougies, and multibeaded, acorn metal dilators and hydraulic pump dilation) which may not available. ${ }^{2}$ In addition, some of these time-consuming techniques are required for fluoroscopic control. The technique described above does not require spacial tools or fluoroscopy.

To avoid any complications during this partially blind procedure, it is necessary to partially open the forceps in the intramural segment of the ureter and gently pull back. At this time, movements that may cause ureteral damage and bleeding (such as excessive and uncontrolled opening and turning and/ or forcing the withdrawal of the forceps) should be avoided.

During ureteroscopy, guidewire is important to ensure success and safety. ${ }^{2}$ However, the European Society of Urotechnology reported that about $33 \%$ of urologists perform the ureterocopy without any guidewire or ureteral catheter. ${ }^{3}$ In our case, the guidewire was not placed at the beginning of the procedure, and yet the operation was not postponed. It

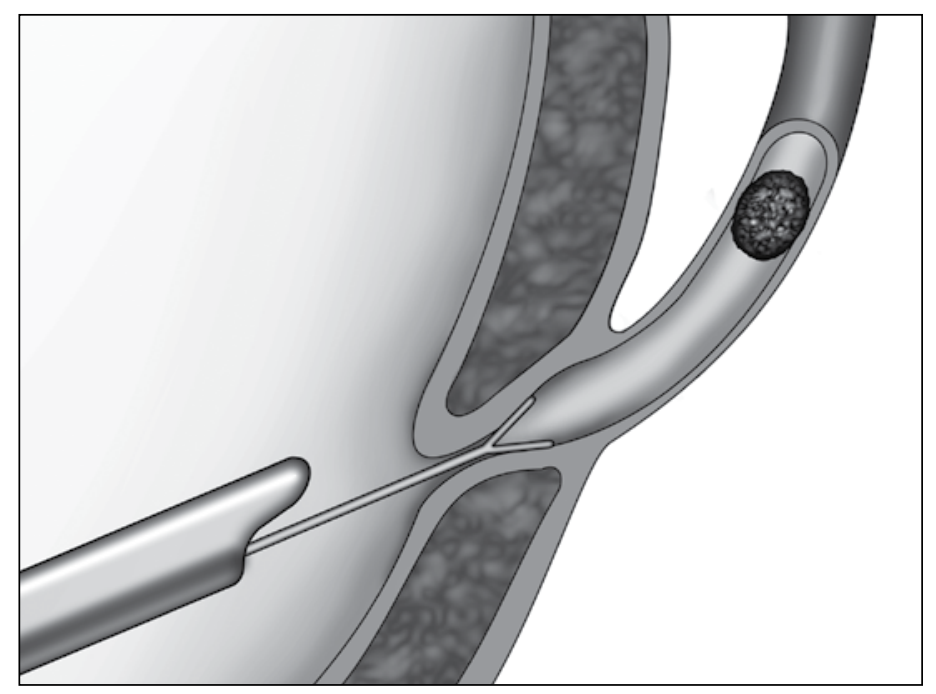

Fig 1. Schematic diagram shows that withdrawal of the grasping forceps. 
is, however, preferable to place the guidewire in the ureter at the earliest opportunity during the ureteroscopy.

\section{Conclusion}

The technique described in this article may be kept in mind when dilatation is not possible with the use of the other dilatation techniques for various reasons. This time-saving and simple technique can be performed in any operating room with basic endourological supplies.

Competıng interests: None declared.

This paper has been peer-reviewed.

\section{References}

1. Warde N. Safety guidewire unnecessary during flexible ureteroscopy for routine cases of nephrolithiasis. Nat Rev Urol 2010;7:645.

2. El-Hakim A, Tan BJ, Smith AD. Ureteroscopy: technical aspects. In: Stoller ML, Meng MV, editors. Urinary stone disease: the practical guide to medical and surgical management. Humana, Totowa, New Jersey, 2007;589-607.

3. Kaver PC, Laguna MP, Alivizatos $G$, et al. Present practice and treatment strategies in endourological stone management results of a survey of the European Society of Uro-technology (ESUT). Eur Urol 2005;48:182-8.

Correspondence: Dr. Cevahir Özer. Nobel Surgical Medical Center, Kenan Evren Boulevard №: 45, Cukurova/Adana, Turkey; mdcevahir@yahoo.com 